\title{
ALÉM DA POLÊMICA DO PROVEDOR: MULHERES, TRABALHO E HISTÓRIA DO TRABALHO ${ }^{1}$
}

Chitra Joshi*

\begin{abstract}
Resumo: Este artigo empreende uma revisão das maneiras pelas quais os historiadores sociais da Índia têm abordado o trabalho feminino, e propõe a necessidade de superar alguns de seus limites. Em meio a um contexto de desindustrialização e de informalização das relações de trabalho na Índia, a autora enfoca as interpretações historiográficas mais estabelecidas, em particular a polêmica do provedor e a consequente exclusão e invisibilização do trabalho feminino em tais contextos. Em seguida, aborda as sugestões de estudos recentes sobre o trabalho rural de mulheres e a migração de homens para as cidades no sentido de questionar as fronteiras entre o trabalho formal e informal. Finalmente, defende a necessidade de se repensar as relações entre trabalho, domesticidade e gênero, numa perspectiva que privilegia as extratégias das mulherees para redefinir noções de domesticidade em suas práticas cotidianas.
\end{abstract}

Palavras-chave: história social, relações de trabalho feminino, gênero, domesticidade.

Abstract: This article develops a review of recent social historiography in India on women's work, and defends the need to go beyond them. In a context of desindustrialization and informalisation of labor relations in India, the author focuses on some historiographical interpretations, particularly the breadwinner debate, and the exclusion and invisibilization of women it entails. The author also reviews recent studies on women's rural work in the context of male migrations to urban settings in order to question the boundaries between formal and informal labor. Finally, she defendes the need to rethink relations among work, domesticity and gender, in a perspective that privileges women's strategies to redefine notions of domesticity int their daily practices.

Keywords: social history, women's work, labor relations, gender, domesticity.

Até muito recentemente não havia nenhum compromisso sério com as questões de gênero e o trabalho das mulheres na escrita da história do trabalho na Índia. Por um lado, porque as mulheres continuam invisíveis nas páginas da história em geral, e os historiadores do trabalho faziam pouco para dar-Ihes visibilidade. Por outro lado, por conta da história do trabalho na Índia permanecer, até recentemente, centrada nas fábricas. O foco exclusivo na fábrica como o local do trabalho produtivo significou a negligência de outros espaços de trabalho, em áreas rurais e nas unidades domésticas. Uma vez que o número de mulheres trabalhando nas fábricas era pequeno, e sua proporção na força de trabalho total decaiu nas décadas iniciais da industrialização, os historiadores do trabalho buscaram recuperar apenas a vida e as experiências da força de trabalho masculina.

Quando os historiadores começaram a escrever sobre as mulheres e o trabalho, eles operaram com categorias que reproduziam pressupostos masculinos. A maior parte dos historiadores do trabalho não conseguia enxergar a variedade do trabalho em que as

\footnotetext{
*Chitra Joshi é professora do Departamento de História do Indraprastha College,, University of Delhi.

${ }^{1}$ Tradução Juliana Guide. Revisão Cristiana Schettini e Fabiane Popinigis.
} 
mulheres estavam envolvidas, nem desenvolveu categorias em que o trabalho feminino pudesse ser conceituado de forma significativa. Neste artigo aponto algumas proposições masculinistas fundamentais, enfatizo a necessidade de ir além delas e de pensar categorias através das quais podemos tornar visível o trabalho das mulheres e entender seus sentidos nas vidas delas. Defendo a necessidade de entender as estratégias que as mulheres desenvolveram para criar espaços para elas mesmas no interior da unidade doméstica, cavando pequenas áreas de autonomia, redefinindo os significados do patriarcado e tensionando os limites do confinamento e da reclusão. Muitos dos temas que levanto sobre a Índia têm ressonância em escritos da América Latina. Criticando estruturas que homogeneízam a experiência das mulheres, historiadores da América Latina também têm apontado para as complexidades e fluidez que caracterizam as relações cotidianas de gênero e poder nas vidas de homens e mulheres. ${ }^{2}$

A necessidade de entender a natureza do trabalho das mulheres na Índia e nos demais lugares é reforçada pelo contexto histórico presente. Dois processos interligados estão se tornando importantes hoje - um, o declínio das tradicionais indústrias fabris de larga escala, como as têxteis; dois, uma tendência à informalização do trabalho - processos que têm sido acompanhados por um crescente emprego do trabalho feminino. Com a informalização, o trabalho está cada vez mais se deslocando de fábricas e espaços públicos para dentro dos lares, becos e quintais. As divisões entre espaço doméstico/ espaço de trabalho, fora/dentro, informal/formal, que sempre foram tênues, parecem agora confundirse. Enquanto alguns dos pressupostos aceitos sobre trabalho e indústria foram criticados durante muitos anos, a presente crise das tradicionais indústrias de larga escala - bastiões da classe trabalhadora masculina - também propicia um contexto em que a necessidade de reconceitualizar relações de trabalho, domesticidade e gênero na escrita da história está se tornando maior.

\section{A IDÉIA DO "PROVEDOR"}

2 Ver, por exemplo, FRENCH, John and JAMES, Daniel, The Gendered Worlds of Latin American Women Workers: From Household and Factory to the Union Hall and Ballot Box Durham: Duke University Press,1997, pp. 1-31, KLUBOCK, Thomas Miller, "Writing the History of Women and Gender in Twentieth- Century Chile", Hispanic American Historical Review, 81:3-4, 2001, 492-518, Heidi Tinsman, 'Reviving Feminist Materialism: Gender and Neo-liberalism in Pinochet's Chile, Signs, 26:1, 2000, pp. 145-88, TINSMAN, Heidi, "Politics of Gender and Consumption in Authoritarian Chile, 1973-1990: Women Agricultural Workers in the Fruit Export Industry", Latin American Research Review, 41:3, October 2006, pp 7-31. 
Ao examinar a história do trabalho feminino e da industrialização no Ocidente, os historiadores concentraram-se repetidamente em um fenômeno chamativo. Nos anos iniciais da industrialização, as mulheres eram vistas como fonte de trabalho barato para a indústria fabril, mas em meados do século dezenove foram substituídas por trabalho masculino qualificado. Porque foi assim?

Nas discussões em torno do fenômeno do "homem provedor" no contexto europeu, podemos identificar várias mudanças. Nas explicações estruturais/econômicas, dominantes nos primeiros trabalhos, assumia-se que o capitalismo produzia uma forma específica de família e sistema doméstico, que servia aos interesses do capital. O trabalho era empurrado para fora de casa e para dentro da fábrica, criando uma separação entre público e privado, lar e exterior. Textos produzidos a partir das décadas de 1970 e 1980 têm questionado o determinismo do velho argumento que enxerga a configuração da família como produto das necessidades inexoráveis do capitalismo, negando as forças históricas que definem as especificidades das diferentes formas de família dentro do sistema.

Dentro desta literatura crítica, duas tendências amplas podem ser identificadas: uma que se concentra na ideologia, e outra, na política institucional. A discussão sobre ideologia toma duas formas. A primeira trata a marginalização das mulheres nos termos da influência das idéias vitorianas de domesticidade e reclusão do século XIX. As ideologias de domesticidade que valorizavam o lugar da mulher em casa, argumenta-se, exerceram uma influência poderosa e moldaram estratégias de empregadores e reformadores burgueses ${ }^{3}$. A imagem da mulher como dona de casa tornou-se um ideal caro ao discurso sindical do período, e para as famílias da classe operária era uma marca de status. A segunda discussão sobre ideologia, tenta entender a dominância do modelo do "homem provedor" em termos de noções de masculinidade. Sugere-se que a autoridade e a identidade masculinas no século XVIII estavam crucialmente ligadas a noções de habilidade e independência. A ideologia de um "salário familiar" para o homem provedor desenvolveu-se como parte de um esforço para preservar essas idéias de masculinidade. Os homens tentaram excluir as

3 Para uma elaboração das noções Vitorianas de domesticidade, ver HALL, Catherine; "The Early Formation of Victorian Domestic Ideology", in White, Male and Middle-Class: Explorations in Feminism and History, Oxford, 1988. 
mulheres dos empregos na indústria para defender seu status e técnica ${ }^{4}$. A importância das idéias masculinistas no interior da sociedade moderna é também enfatizada na teoria do contrato sexual de Carol Paterman. Paterman defende que as noções de cidadania e contrato social na sociedade burguesa eram fundamentalmente distorcidas, assentadas como eram num contrato sexual que subordinava e excluía as mulheres da esfera política pública. ${ }^{5}$ Nestes moldes, a idéia de um homem provedor é essencial para uma sociedade assentada na separação entre espaço público e privado, e entre local de trabalho e espaço doméstico.

As discussões em torno da política institucional e da emergência do homem provedor centram-se na política dos sindicatos e das estratégias excludentes dos empregadores. ${ }^{6}$ Os sindicatos exigiam um salário familiar para o homem provedor e tentavam preservar os privilégios masculinos excluindo as mulheres dos empregos nas fábricas. As estratégias dos empregadores no fim do século dezenove marginalizavam a mão de obra feminina e reforçavam a família do homem provedor.

Muitos dos assuntos levantados no debate do provedor continuam a inquietar os historiadores que escrevem sobre gênero e trabalho, ainda que a universalidade de qualquer prática única seja questionada. Os historiadores agora apontam para a variedade de práticas provedoras e para a ausência de uma norma reguladora. ${ }^{7}$ Uma preocupação exclusiva com a questão do homem provedor tende a obscurecer as variedades de trabalho em que estão engajadas as mulheres em casa e fora dela. O foco nas ideologias de domesticidade e nas noções de masculinidade revela algumas das formas dentro das quais a política de gênero opera, com os termos de inclusão e exclusão ou os processos de valorização e desvalorização do trabalho. Uma compreensão da política dos sindicatos e das estratégias dos empregadores mostra como formas de discriminação de gênero tornam-se sedimentadas com o tempo. Ainda assim, em grande parte desta historiografia - seja enfocada nas determinações econômicas estruturais, seja nas ideologias ou na política institucional - as vozes das mulheres permanecem silenciadas. Os processos cotidianos de negociação,

\footnotetext{
4 Veja, por exemplo, ROSE, Sonya, "Gender at Work: Sex, Class and Industrial Capitalism", History Workshop, 21, 1986, pp.113-31.

PATEMAN, Carole; The Sexual Contract, Stanford University Press: Califórnia, 1988.

6 WALBY, Sylvia; Patriarchy at Work (Oxford 1986), Wally Seccombe, Weathering the Storm: Working Class Families from the Industrial Revolution to the Fertility Decline. Verso: London, 1993.

7 Ver, por exemplo, JANNSENS, Angelique, "The Rise and Decline of the Male Breadwinner Family? An Overview of the Debate", International Review of Social History, 42,1997, pp 1-23.
} 
aquiescência e contestação que remodelam essas estruturas de poder permanecem fora do alcance destes debates.

Considerarei agora a discussão da forma como se desenvolveu na Índia.

\section{A POLÍTICA DA EXCLUSÃO}

Um importante estudo recente sobre as mulheres na indústria da juta de Bengala, feito por Samita Sen, centra-se nos padrões, determinados pelo gênero, de migração para as fábricas e na marginalização das mulheres ao longo do tempo. Sen desloca o foco dos processos econômicos e observa a interação entre os fatores estruturais, institucionais e ideológicos para entender o deslocamento das mulheres da força de trabalho industrial ${ }^{8}$. Sen explora como as idéias de domesticidade e reclusão, influenciadas pelas noções vitorianas e brâmanes de moralidade e respeitabilidade tornaram-se poderosas na Bengala do final do século XIX. Na Bengala rural, famílias com capital retiravam as mulheres dos trabalhos fora de casa. Nas famílias mais pobres, porém, as mulheres continuaram a exercer atividades produtivas fora de casa, um fenômeno que se intensificou com a migração masculina para a cidade.

Migração e trabalho urbano, no entanto, significaram uma desvalorização geral do trabalho feminino nas áreas rurais e a glorificação do trabalho assalariado masculino nas cidades. Nas fábricas de juta em Calcutá ocorreram, ao mesmo tempo, a marginalização e a desvalorização do trabalho. Sen mostra como uma mudança de trabalho local para distante, por volta da década de 1890, foi acompanhada por um declínio na já pequena porção de mulheres trabalhadoras. A estratégia dos empregadores ao longo dos anos estruturou diferenciações de habilidade, desvalorizando o trabalho das mulheres e valorizando o trabalho masculino. As mulheres acabaram por se concentrar em trabalhos que pagavam menos, e também foram as primeiras a ser atingidas pelos esquemas de racionalização e mudança tecnológica. Utilizando-se do discurso da domesticidade, os gerentes legitimaram a

8 SEN, Samita; Women and Labour in Late Colonial India, Cambridge: Cambridge University Press: 1999. Outros como Radha Kumar relacionam a queda na proporção de mulheres trabalhadoras em Bombaim a mudanças na tecnologia e ao processo de racionalização da indústria têxtil após 1929. KUMAR, Radha, "Family and Factory: Women in the Bombay Cotton Textile Industry 1919-1939", in KRISHNAMURTHY, J. ed. Women in Colonial India, Delhi: OUP, 1989, p.151. 
crescente marginalização das mulheres, e a política das associações dominadas por homens reforçaram estas tendências. Famílias trabalhadoras compartilhavam os pressupostos deste discurso e mulheres de grupos de maior renda tendiam a deixar a força de trabalho. Tão difundida era a prática de desvalorizar o trabalho feminino que até os ganhos de mulheres viúvas e abandonadas, usualmente das castas mais baixas, continuavam a ser caracterizados oficialmente como "suplementares". No contexto do pós-guerra, quando filantropos, reformadores e agentes do Estado articularam a preocupação em torno do bem estar da família e da maternidade, a maioria dos empregadores preferiu se livrar do trabalho das mulheres em geral a introduzir uma legislação protetora.

O estudo de Samita Sen mapeia com muita clareza os cálculos dos empregadores e mostra porque as mulheres foram excluídas da força de trabalho industrial. Este é um fenômeno que precisa ser reconhecido. Ainda assim, penso que podemos levar a discussão sobre a exclusão mais longe. O que realmente significa exclusão? O que a retirada para a aldeia ou para o lar realmente implica?

Discussões sobre trabalho e gênero tendem a pressupor que as mulheres excluídas da força de trabalho se retiraram para a domesticidade e a reclusão. O domínio de dentro da casa é visto como um espaço de obediência e subordinação, um local onde as mulheres desempenham os papéis de mães, esposas e donas de casa. Nesses moldes, as mulheres só podem desempenhar papéis transgressores fora do doméstico. As inumeráveis negociações e contestações que permeiam a vida cotidiana das mulheres dentro de casa não constituem objeto de investigação. Argumento que as noções de domesticidade e reclusão não foram dadas; foram construídas e definidas de formas específicas em situações específicas. A aceitação pública das normas de reclusão pode conviver com transgressões privadas, e significados particulares de aceitação e não-aceitação poderiam ser redefinidos em contextos diferentes. Precisamos entender como esses conflitos se davam.

Mesmo nos moldes de uma ideologia dominante de domesticidade, mulheres das famílias da classe trabalhadora com freqüência criavam seus próprios códigos, assim como mulheres que exerciam trabalho remunerado os desenvolviam em sua luta para preservar um senso de dignidade. Ainda assim, a asserção pública dos códigos dominantes pode coexistir com a subversão. O foco numa ideologia generalizante limita as possibilidades de enxergar modificações interiores e maneiras particulares em que a ideologia se transforma. 
Tento me debruçar sobre algumas destas questões examinando narrativas orais de mulheres em tempos mais recentes.

\section{MULHERES, FAMÍLIA E REPRODUÇÃO: REPENSANDO O RURAL}

O argumento de que a família trabalhadora foi crucial na reprodução do poder do trabalho não é nova. Ele figurou de forma significativa em discussões sobre o trabalho das mulheres na Índia no contexto europeu dos anos setenta, embora a escrita da história, especialmente na Índia, tenha sido majoritariamente masculina e centrada nas fábricas. Isso criava dois tipos de exclusões: um, o papel mais amplo da família da aldeia na reprodução do trabalho não é levado em consideração; dois, o foco destes textos é no homem provedor da família urbana, excluindo outros tipos de práticas de sustento, especialmente as realizadas pelas mulheres.

A persistente relevância dos laços rurais para os migrantes da classe trabalhadora na cidade é claramente reconhecida na maior parte dos textos. No entanto, esses laços são usualmente examinados a partir dos pagamentos masculinos enviados às suas aldeias de origem. Os pressupostos masculinistas que classificam os ganhos dos homens como "principais" e os das mulheres como "suplementares" estruturam a maior parte das discussões sobre as famílias da classe trabalhadora. Não apenas as pesquisas oficiais sobre orçamentos familiares foram estruturadas nestes termos, mas os saberes populares locais também comemoravam a remessa do dinheiro vivo feita pelos homens. Eram ganhos que podiam resgatar propriedades e pagar dívidas. Em Bhojpur, no Norte da Índia, uma área que mandou migrantes para as fábricas e para as minas, um dito popular dizia o seguinte: "Aquele que consegue um emprego no leste pode encher sua casa de ouro" ${ }^{9}$. O outro lado - por exemplo, a contribuição da família na aldeia, particularmente das mulheres na 'reprodução do trabalho', é raramente reconhecido.

9 Citado em Nirmala Banerjee, "Working Women in Colonial Bengal: Modernisation and Marginalization", in SANGARI, KumKum e VAID, Sudesh; ed. Recasting Women: Essays in Colonial History. New Delhi: Kali for Women, 1989, p.294. 
Textos recentes firmam um importante ponto de partida ao esboçar as ligações entre o trabalho rural das mulheres e a migração dos homens para as cidades. ${ }^{10}$ As mulheres em famílias rurais eram importantes para semear, extrair ervas daninhas, colher, peneirar quase todas as operações para além do lavrar a terra. A contribuição das mulheres dentro da família tornou-se essencial no fornecimento das ligações que conectavam a família trabalhadora da cidade com a aldeia. Aquelas que não estavam cultivando os campos se envolveram numa gama de outras atividades da produção e busca por alimento: recolher esterco de boi, lenha, pasto, fabricar cestos, descaroçar algodão, fiar, bater e descascar arroz, moer farinha, fabricar laticínios, óleos vegetais e produtos da floresta estavam dentre as muitas ocupações possíveis. Uma grande proporção de mulheres eram empregadas no descascamento de arroz; uma ocupação que fornecia não só uma renda suplementar, mas que era comumente a única alternativa de famílias camponesas pobres ${ }^{11}$. Durante tempos de crise, famílias camponesas pobres sobreviviam com os ganhos conseguidos pelas mulheres no descascamento de arroz. $E$ isso não apenas trazia mais renda que atividades tradicionais como fiar, mas também era considerado socialmente aceitável por diferentes grupos sociais. Ao contrário do trabalho feito em fábricas de arroz, o descascamento tradicional era feito na privacidade do lar, e não em espaço público. A introdução das modernas fábricas de arroz por volta da década de 1920, no entanto, significou uma queda no emprego das mulheres. Isso as afetou negativamente nas famílias mais pobres: tornou a subsistência mais precária e privou-as do controle de recursos vitais para a família.

As histórias alternativas, assim, precisam inverter a perspectiva e considerar as ligações entre a trajetória econômica das famílias da classe trabalhadora e os ritmos de trabalho das mulheres. O que acontece com as famílias em períodos de escassez? Quais são as conseqüências dos deslocamentos? Quais são suas implicações para as famílias da classe trabalhadora? A pressão sobre os ganhos nas áreas rurais obviamente criaria problemas para as famílias da classe trabalhadora, tornando difícil que elas satisfizessem as necessidades do consumo. O valor relativo do salário industrial dos homens - ou seja, a

10 Sen, por exemplo, aponta para o crescente envolvimento das mulheres na economia rural no distrito de Saran - que forneceu o maior número de migrantes para Calcutá. Women and Labour in Colonial India, pp.7172.

${ }^{11}$ O estudo de Mukul Mukherjee mostra como nas primeiras décadas do século XIX, uma grande proporção de mulheres em Bengala estavam empregadas no descascamento de arroz: 2131 em 1901, 2703 em 1911. "Impact of Modernization on Women's Occupations: A Case Study of Rice Husking Industry of Bengal", Economic and Social History Review, 20:1,1983, pp.27-45 
renda daqueles que estavam em áreas industriais - dependeria então dos ganhos das mulheres nas áreas rurais e dos ritmos e temporalidades do trabalho rural. Freqüentemente se observa que as mulheres tendem a entrar no mercado de trabalho urbano em tempos de abundância e a se retirar dele quando a demanda por trabalho cresce e os salários estão subindo. Esse fenômeno ocorre precisamente porque a oportunidade de trabalho nas áreas rurais é essencial para a reprodução das famílias trabalhadoras, e isso sobredetermina a condição da unidade doméstica da classe trabalhadora.

A pesquisa histórica sobre o trabalho precisa explorar essas ligações e considerar a contribuição das mulheres para a família da classe trabalhadora. Para entender o significado de sua contribuição, temos que nos afastar de um viés urbano e centrado nas fábricas.

Dentro do contexto urbano, também, a suposição do homem provedor como norma na maior parte dos textos significou subestimar as diferentes formas através das quais as mulheres sustentaram famílias da classe trabalhadora. A noção do homem provedor, nunca uma categoria adequada para análise histórica, tem pouco significado no atual contexto, em que os homens estão cada vez mais desempregados. Este é um tópico que retomo ao tratar a questão da informalização e do trabalho.

\section{INFORMALIZAÇÃO E O TRABALHO DAS MULHERES}

Ao examinar a questão da informalização e das mulheres, a tentativa aqui não é a de concretizar distinções entre o formal e o informal. Os limites entre os dois, como nós sabemos, e especialmente no caso das mulheres, sempre foram pouco claros. $\mathrm{O}$ trabalho das mulheres, mesmo formal - em grandes fábricas - teve com frequência um caráter informal. A ausência de regulação, a insegurança de contratos e a ausência de direito à organização foram traços característicos do trabalho das mulheres. Na Índia, como em muitos outros países do sul do globo, as décadas a partir dos anos 1980 foram tempos em que o emprego de mulheres nos postos da indústria adquiriu importância crescente. No caso da América Latina, também uma série de trabalhos aponta para a crescente importância do doméstico como um local de trabalho remunerado. O processo denominado por alguns de 
'housewifization' ${ }^{12}$ do trabalho faz referência às flexíveis, mal pagas e segregadas formas de trabalho em casa. ${ }^{13}$

Nos núcleos pioneiros de cidades industriais como Kanpur, no Norte da India, o trabalho das mulheres terminou sendo associado a duas formas diferentes de ocupação, localizadas em dois espaços distintos, cada um com suas próprias características. Primeiro, uma série de atividades invisíveis tornaram-se cada vez mais importantes. As mulheres costuravam, enrolavam bidis $^{14}$, embrulhavam balas, cortavam tiras de borracha para chinelos, faziam a parte de cima de sandálias de couro, vassouras, incensos e uma série de outros pequenos trabalhos remunerados em casa. ${ }^{15} \mathrm{~A}$ proliferação destas formas de trabalho implica uma crescente invisibilidade do trabalho na esfera pública, e um recuo dele para o domínio do doméstico. Membros homens das famílias, ou às vezes as próprias mulheres, coletam matéria prima para confeccionar bidis, ou para fazer tiras para chinelos e outros tipos de tarefas intermediárias e a trazem para casa. Trabalhos como estes permitem às mulheres combinar domesticidade com trabalho remunerado, mas redefinem a natureza de seu relacionamento com o doméstico de formas significativas. Atividades como a fabricação de bidi - envolvendo o processo de secar, cortar, preencher, enrolar e amarrar os bidis invadem completamente o doméstico, levando quase o dia inteiro. Há sempre uma pressão para produzir mais porque os preços são usualmente em torno de 20 rúpias (Rs.) a cada 1000 bidis (menos de 50 centavos de dólar) e é necessário o trabalho de uma família inteira (ou de duas a três mulheres) por um dia inteiro para confeccionar este número.

O trabalho informal deste tipo é assim fragmentado em pequenas unidades domésticas, não regulamentadas por nenhum tipo de legislação. Ele permite aos empregadores fazer uso de estratégias de trabalho flexíveis e reduz os custos do trabalho ao

12 O termo deriva da palavra housewife (dona de casa), e descreve o processo pelo qual as mulheres passam a ser definidas socialmente como tal, enquanto os homens são definidos como provedores. $O$ termo foi inicialmente proposto pela socióloga Maria Mies para uma análise das origens sociais da divisão sexual do trabalho em Patriarchy and accumulation on a world scale: women in the international division of labour, Zed Books, 1986. [Nota das editoras].

13 Ver, por exemplo, BOSE, Cristine E. e ACOSTA-BELEN, Edna, “Colonialism, Structural Subordination and Empowerment" em Women in the Latin American Development Process (Temple University Press, 1995), pp. 15-36, e SAFA, Helen, "Economic Re-Structuring and Gender Subordination" Latin American Perspectives, 22:2, Spring 1995, pp.32-50

14 Bidi = tabaco seco enrolado numa folha de tendu, depois fumado. Os Koris estavam tradicionalmente envolvidos na fabricação.

15 Por volta de $90 \%$ da força de trabalho na indústria do bidi na Índia consiste de mulheres e crianças. 
mínimo. A ausência de tradições de organização coletiva nos trabalhos remunerados feitos em casa torna esses tipos de trabalho informal particularmente atraente para o capital.

As mulheres também eram empregadas em formas de produção que eram mais visíveis e coletivas. As novas indústrias que surgiram desde os anos 1980 - eletrônicos, artigos esportivos, vestuário - eram baseadas com freqüência no emprego do trabalho de mulheres. Consideremos um exemplo. A expansão da indústria de malhas em Tiruppur, no Sul da Índia, a partir de meados da década de 1980, era estruturada em torno ao trabalho das mulheres. Tiruppur tornou-se um centro da indústria de malhas na década de 1970, quando o capital saiu de centros com movimento operário poderoso como Calcutá. Inicialmente as mulheres trabalhavam como ajudantes; em suas casas. Porém, o crescimento da produção para exportação, de 1985 para frente, baseou-se no crescente emprego de mulheres em pequenas unidades responsáveis por operações de corte e costura. ${ }^{16} \mathrm{~A}$ expansão da produção de malhas em Tiruppur, como em muitas indústrias exportadoras que surgiram na década de 1980, é baseada nos sistemas de subcontratação e informalização. Os processos de produção são sustentados por numerosas pequenas unidades que empregam jovens mulheres - que usualmente tinham entre 15 e 20 anos de idade - em contratos casuais de pagamento por peça, rendendo uma remuneração diária que dificilmente atinge um pouco menos da metade do salário mínimo na área. ${ }^{17}$

Esta forma de produção oferece poucas possibilidades de organização: a cadeia de subcontratação e a natureza sazonal do trabalho limitam a capacidade de negociação dos trabalhadores. Na verdade, a preferência por mulheres em pequenas unidades como em Tiruppur se dá precisamente porque permite uma administração que empregue estratégias de trabalho flexível, com a possibilidade de regular a oferta de trabalhadores de acordo com as necessidades flutuantes da produção.

O emprego de mulheres na última década reflete um processo de feminização do trabalho? As discussões sobre a questão da feminização do trabalho se moveram entre visões comemorativas de trabalho como fator de autonomia e poder para as mulheres e concepções críticas questionando esta idéia de empoderamento. Os pessimistas

16 Hoje as mulheres constituem $60 \%$ do total da força de trabalho em Tiruppur. Ver NEETHA, N., "Flexible Production, Feminisation and Disorganisation: Evidence from Tiruppur Knitwear Industry", Economic and Political Weekly, 37:21, May 2002, pp. 2045-2052

17 A maior parte das categorias de mulheres recebia salários menores ou iguais a Rs. 50 por dia. Nas categorias qualificadas, os salários variavam entre Rs. 40 e Rs. 80 por dia. 
freqüentemente minam o significado do trabalho das mulheres no geral, argumentando que a arrancada inicial no emprego delas até meados de 1990 foi seguida por uma queda. Entre 1991 e 2001 o índice de participação das mulheres no trabalho mostra um declínio de 15,6 \% em 1991 para 11,4\% em 2001 - uma queda de mais de 4 pontos percentuais. ${ }^{18}$ Além disso, eles tendem a descartar a idéia do empoderamento, apontando para os termos extremamente inseguros dos empregos e os baixos salários que as mulheres recebem. ${ }^{19}$

Há problemas nestes argumentos. Em primeiro lugar, os indicadores estatísticos de declínio no emprego das mulheres não são adequados. As informações do National Sample Surveys (NSS) em que esses indicadores são baseados referem-se somente a unidades registradas, e não às inumeráveis variedades de trabalho. Em segundo lugar, uma vez que há uma queda no emprego de mulheres, ela está ligada a uma tendência de queda no emprego em geral, não sendo específica das mulheres. Além disso, os números que indicam queda não consideram as várias formas de trabalho invisíveis, feitas em casa, que ainda proliferam.

Críticos da tese da feminização tendem a assumir que qualquer reconhecimento do emprego das mulheres sugere uma idéia de empoderamento. Meu ponto aqui não é fazer uma conexão reducionista entre trabalho assalariado e empoderamento. Eu defendo a necessidade de propor questões diferentes. Em primeiro lugar, precisamos examinar a relevância do trabalho na redefinição da auto-percepção das mulheres e de suas relações com a casa e o exterior. Isso é difícil, principalmente quando examinamos o passado. 0 problema do não reconhecimento do trabalho das mulheres é comum às narrativas oficiais e não oficiais.

Os próprios julgamentos das mulheres estão constantemente estruturados pelas normas de família e de casta; o privilegiar o trabalho ou não-trabalho é constantemente determinado por essas convenções. Em segundo lugar, precisamos considerar as maneiras pelas quais as mudanças nas condições de emprego afetam a produção de identidades de gênero, tanto masculinas quanto femininas. O presente contexto de queda na oferta de empregos para homens, especialmente nos velhos centros, também significou uma crise na masculinidade. Se a fábrica era a esfera na qual noções de masculinidade eram construídas,

18 GHOSH, Jayati, “Macroeconomic Reforms and Labour Policy Framework of India”, www.networkideas.org, 13 Fevereiro, 2003, p. 24

19 Ver por exemplo, GHOSH, Jayati, “Informalisation and Women's Workforce Participation: a Consideration of Recent Trends in Asia", www.networkideas.org, 28 Abril, 2004, pp.20-28 
seus deslocamentos no presente desalojaram essas identidades. O que esse sentimento de emasculação significa para as famílias da classe trabalhadora? Retornarei a este ponto depois.

\section{COMO AS MULHERES VÊEM O TRABALHO E O NÃO-TRABALHO}

Discussões a respeito da emergência do "homem provedor" constantemente enquadram as múltiplas experiências das famílias das classes trabalhadoras em um padrão uniforme. As vidas das mulheres, no entanto, contam histórias diversas e incorporam experiências de domesticidade variadas. Neste ensaio tento examinar diferentes noções de domesticidade expressas em suas experiências, debruçando-me sobre as narrativas orais de mulheres trabalhadoras ${ }^{20}$.

Argumentos que pressupõem a influência hegemônica das idéias de domesticidade, com freqüência obscurecem a importância do trabalho nas vidas das mulheres. Não é fácil para mulheres que antes trabalharam em fábricas resignar-se à perda daquela posição. Em seus relatos, o trabalho fabril é valorizado porque lhes dava uma sensação de segurança.

Mulheres que trabalharam em fábricas têxteis até a década de 1990 continuaram a atribuir significados à posição de trabalhadoras fabris. Suas narrativas são norteadas pela nostalgia: as longas horas, as estruturas opressivas de autoridade nas fábricas são com frequência apagadas nos momentos de recordação. Para elas, as longas horas que passavam em pé na fábrica eram mais significativas do que aquelas que passavam sentadas. ${ }^{21} \mathrm{O}$ poder da ideologia patriarcal não domesticara plenamente as mulheres excluídas do trabalho fabril dentro de um molde rígido. Assim, outras mulheres, envolvidas em atividades remuneradas em casa viam seu trabalho como pequeno e insignificante, sugerindo uma comparação implícita com outras formas de trabalho fora de casa, mais formais e tidas como mais importantes.

20 Baseei meu estudo em narrativas orais de mais de 100 famílias.

21 "Nós trabalhávamos nas bobinas, de pé o dia inteiro, e agora nos sentamos ociosas". O contraste entre estar parado 'de pé' e estar parado 'sentado ' nesta fala é expressivo da transição do trabalho para o nãotrabalho. Entrevista com Munni Devi, que trabalhou nas Swadeshi Cotton Mills, em Kanpur, por quase 25 anos. Ela, como muitas outras mulheres trabalhadoras, esvaziava as bobinas de máquinas. 
Os trabalhos em fábricas, nessas narrativas, são associados a percepções de talento e orgulho, em contraste com o trabalho feito em casa, despossuído destes atributos.

As noções de trabalho e domesticidade para as mulheres que ficam em casa são perpassadas por uma série de temas - por questões de pureza e mácula, por percepções de casta e status e pelas necessidades de sobrevivência econômica. A escolha do trabalho pelas mulheres é condicionada por uma variedade de considerações. Às vezes, áreas específicas vêm a ser associadas com certas tradições do trabalho das mulheres. Em áreas como Baconganj, em Kampur, onde mulheres muçulmanas estão envolvidas na costura de burqas (véus), a costura pode parecer uma escolha natural para as mulheres, enquanto em outras vizinhanças a fabricação de bidi é o único trabalho disponível para elas. Em áreas próximas às fábricas de calçados de plástico, mulheres trançam tiras de plástico para sandálias de dedo ${ }^{22}$. Em localidades em que não há tais tradições de trabalho, a domesticidade aparece como norma. Alguns tipos de trabalho são considerados socialmente humilhantes por castas específicas. Famílias da classe trabalhadora que melhoraram seu status social são mais rígidas a respeito das normas de reclusão. As mulheres nessas famílias viam trabalhos de costura como sendo mais respeitáveis que a fabricação de bidis, mas até isso envolvia conflitos intensos com as estruturas patriarcais da família. O trabalho era com frequência feito clandestinamente, longe dos olhos desaprovadores dos membros da família e dos vizinhos.

Com a proximidade das fábricas em cidades industriais como Kanpur, as estratégias familiares estão sendo redefinidas. Em muitas famílias da classe trabalhadora, os ganhos das mulheres provenientes do trabalho remunerado feito em casa e fora de casa estão se tornando crescentemente importantes. ${ }^{23}$ Há, de qualquer forma, diferenças. Castas e idéias de status e respeitabilidade medeiam as atitudes em relação ao trabalho remunerado.

A classe trabalhadora de castas mais altas (brâmanes e rajputs, por exemplo) preferia proteger seu status e posição proibindo as mulheres de fazer trabalhos remunerados. Para esta, a honra e a dignidade de uma família estavam associadas à reclusão das mulheres: o

22 Chappals.

23 Num estudo sobre famílias rurais no distrito de Allahabad, na década de 1980, os ganhos das mulheres provenientes da fabricação de bidis contribuíram com $85-95 \%$ da receita anual nas famílias mais pobres. Ver BHATTY, Zarina; "Economic contribution of women to ht household budget: a case study of the beedi industry", in SINGH, Andrea M. and KELLES-VIITANENE, ed. Invisible Hands: Women in Home-Based Production. New Delhi: Sage Publications 1987, p.42. 
trabalho remunerado feito pelas mulheres era visto como uma transgressão e uma violação da honra da família. O que acontece nessas unidades domésticas quando o homem trabalhador é demitido? Nessas famílias, as idéias de domesticidade definiam sua resistência contínua ao trabalho das mulheres, a despeito do aperto financeiro. No caso dos que ainda tinham ligações com suas aldeias de origem, as mulheres retornavam a elas, enquanto os trabalhadores demitidos procuravam por trabalho no setor informal. ${ }^{24}$ Ao contrário das convencionais histórias de migração, em que camponeses se deslocavam do interior para a cidade, nestes casos o que se vê é um movimento contrário, de volta para as aldeias. Outras famílias, que não tinham as mesmas proibições em relação ao trabalho das mulheres em termos de casta ou de status ritual, apropriavam-se de práticas de reclusão quando os trabalhos nas fábricas eram disponíveis e os ganhos dos homens eram mais substanciais. Num contexto em que os trabalhos para homens estavam em queda, é difícil manter esses marcadores de respeitabilidade. Muitas mulheres deste cenário agora estão sendo empurradas para o trabalho, na ausência de um homem provedor. Enquanto algumas procuram trabalhos que percebiam como adequados, como costurar e fazer acabamentos em unidades domésticas de produção de roupas íntimas e meias, outras são forçadas a trabalhos como a produção de bidis, que consideravam socialmente aviltantes. ${ }^{25}$ Ainda assim, mesmo nas castas mais baixas não há uma reação uniforme. Algumas mulheres das chamadas castas "intocáveis", com uma longa tradição de trabalho fora de casa como catadoras de lixo e outros dejetos são agora enfáticas a respeito dos tabus de reclusão para as mulheres mais novas em suas famílias. Tais significantes de status e hierarquia pareciam a elas essenciais num mundo que tendia a estigmatizá-las como impuras. 0 mundo além dos muros da casa aparece em tais relatos como uma zona perigosa que as mulheres não devem ultrapassar. O mundo além dos muros da casa aparece em tais relatos com uma zona perigosa que as mulheres não devem ultrapassar. Histórias como essas mostram que as mulheres que forjavam uma vida independente para si, fora das estruturas convencionais do patriarcado, participavam ativamente do reforço às normas de reclusão para mulheres.

24 Entrevista, Ranno Devi, de berço kshatriya (casta guerreira).

25 Mulheres como Ram Pyari, que agora fazem bidis, falam dos dias em que as mulheres da casa de seu marido não trabalhavam: "Meu sogro trabalhava numa fábrica então minha sogra não trabalhava" . A vida é diferente para sua geração, em que não há trabalho deste tipo para os homens. O marido dela é vendedor de verduras. Entrevista, Ram Pyari. 
Como o trabalho remunerado transformou as relações de gênero e poder em casa? Argumentos generalizantes sobre a dominância do controle patriarcal e dependência das mulheres tendem a obscurecer as complexas transações e negociações que reforçam as relações de gênero na família. O trabalho remunerado realizado pelas mulheres abriu possibilidades de contestação na esfera do consumo doméstico. As mulheres podiam exercer maior controle sobre como a renda era gasta e contestar a autoridade masculina nestes assuntos. No passado, mulheres trabalhadoras de famílias extensas, com estruturas consolidadas de hierarquia e autoridade, praticamente não tinham qualquer controle sobre sua renda. O relatório de uma pesquisa realizada em 1939 era categórico: nenhuma mulher, - casada ou não -, tem qualquer direito de dispor de sua renda de forma independente. ${ }^{26} \mathrm{O}$ relatório diz ainda que mesmo as viúvas incluídas na pesquisa não tinham direitos independentes sobre sua renda. A luta pelo controle da economia doméstica envolvia conflitos entre noções femininas de parcimônia e de desperdício masculino. Para muitas mulheres, trabalho e ganhos independentes eram formas de definir estilos de vida, de estabelecer um regime de parcimônia na família. Isso era em parte resultado da necessidade: era a única forma através da qual as mulheres podiam lidar com o que elas viam como extravagância masculina. Mulheres nas famílias, em particular de castas mais baixas, declaravam que os homens tendiam a consumir tudo o que elas ganhavam. ${ }^{27}$ Mesmo quando os tempos eram melhores e os homens tinham mais empregos, a contribuição deles para a economia doméstica, de acordo com as mulheres destas famílias, era marginal. $\mathrm{Na}$ maior parte das famílias das castas mais baixas as mulheres zombavam abertamente de que os homens gastavam todos os seus ganhos em bebida. ${ }^{28}$ No presente contexto, em que os ganhos masculinos são irregulares, as mulheres freqüentemente têm maior controle sobre os recursos familiares. Mulheres de muitas famílias das castas mais baixas foram categóricas em dizer que elas definiam os limites da extravagância masculina através de um controle

\footnotetext{
26 "Report on the earnings of women mill-workers in Cawnpore." Labour Bulletin, 1:4.

27 "Por volta de $10 \%$ dos homens de nossa casta sobrevivem dos ganhos das mulheres". Entrevista, Shyama.

28 Mulheres como Shyama, que trabalhou a vida inteira como varredora municipal e agora tem por volta de setenta anos, afirmam: "Os homens ganham, mas desperdiçam seu dinheiro com bebidas e casos com mulheres.". Entrevista, Shyama. Outras insistem que é inútil pedir dinheiro aos homens: "Se reclamarmos que está difícil de levar, os homens nos dizem para ir embora com outro". Entrevista, Sunita. Este era um prédio habitado majoritariamente por famílias da comunidade "intocável" Kureel, que antes trabalhavam em estabelecimentos de couro. Agora, as famílias dependem quase que inteiramente dos ganhos conseguidos pelas mulheres nas indústrias de algodão.
} 
mais rígido sobre o orçamento familiar. Elas foram enfáticas ao dizer que os homens não tinham permissão para tirar o dinheiro da bebida dos ganhos das mulheres.

Trabalho e salários às vezes permitiam uma ruptura mais radical das estruturas de autoridade na família. Nas narrativas de mulheres há, com freqüência, uma relação contraditória entre a idéia do trabalho remunerado como degradante, de um lado e, do outro, a do trabalho como gratificante e fortalecedor. Em raros casos, ainda que notáveis, as mulheres foram capazes de se separar da família expandida e estabelecer núcleos domésticos independentes. O reconhecimento de sua agência e autonomia em tais histórias é continuamente sobrepujado pelas narrativas de necessidade e vitimização. Talvez seja só através destas estruturas que o trabalho adquira significado e legitimidade em suas vidas. ${ }^{29}$

\section{REDEFININDO A RECLUSÃO, ABRINDO ESPAÇOS}

Os argumentos sobre o poder hegemônico das idéias de reclusão pressupõem uma oposição entre o mundo de fora e o domínio interior da família. Os limites da casa, neste argumento, parecem fechados e impenetráveis. A retirada das mulheres da esfera pública seu recuo para os interiores da casa - as separa do mundo de fora. Eu argumento aqui que os limites da reclusão, e os termos em que o doméstico era definido, eram objeto de negociação e mudança. ${ }^{30}$

As mulheres que não trabalhavam em fábricas de produção em larga escala não estavam sempre confinadas no interior da casa. Mulheres de castas mais baixas, em geral necessitadas e viúvas, estavam envolvidas numa variedade de ocupações fora da casa. Em cidades como Kanpur há casos de mulheres viajando para muito além de sua vizinhança para trabalhar em pequenos estabelecimentos; mulheres como Sukhrani, viúva e sem nenhum

29 Era comum às suas narrativas um sentimento de satisfação com o seu próprio papel na educação e criação das crianças. Entrevistas com Asha, Shyama, Kamla Gangotri e outras.

30 Em outro trabalho elaborei os diversos sentidos da reclusão. Para muitas mulheres, morar na cidade redefiniu os limites do patriarcado de formas importantes. A cidade aliviou pressões cotidianas que elas experimentavam nas vilas. Os códigos de vestuário e comportamento para mulheres eram mais rígidos nas aldeias do que nas cidades. Mulheres como Shakeela, cujos parceiros trabalhavam em Kanpur, vinham à cidade periodicamente como uma forma de escapar à parentela do marido na aldeia. Ela preferia ficar dentro de casa na cidade a ficar na aldeia. A cidade significava descanso para ela. Os limites da sua mobilidade na cidade eram ainda determinados pelo seu marido, mas mulheres como Shakeela experimentavam uma sensação de liberdade na cidade, em contraste com a não-liberdade das aldeias. Entrevista, Shakeela. 
apoio familiar, que andava de três a cinco quilômetros todo dia para trabalhar em pequenos estabelecimentos de manufatura de cerdas. ${ }^{31}$ Outras trabalhavam em fábricas de bolsas e em fábricas de roupas íntimas e meias. ${ }^{32}$ Algumas até trabalhavam à noite em fábricas fazendo arreios de couro, em períodos que o trabalho era mais pesado.

As mulheres envolvidas nos trabalhos feitos em casa não eram necessariamente confinadas aos seus lares, reclusas do mundo. Elas interagiam com o exterior - com comerciantes e mercados - coletando matéria prima e entregando mercadorias. Mulheres de famílias de castas mais baixas, cortando tiras de borracha para calçados, deslocavam-se regularmente para recolher matéria-prima nas fábricas e entregar o produto final aos comerciantes. As que buscavam o material diretamente na fábrica podiam ganhar de $30 \%$ a $40 \%$ a mais do que aquelas que dependiam de intermediários que trouxessem a matéria prima para suas casas. Mulheres de castas que se consideravam superiores, no entanto, raramente saiam elas mesmas para comprar material. O medo da censura familiar tornava difícil para elas lidar diretamente com o mercado, ainda que isso significasse ganhos menores. $^{33}$

De qualquer forma, as mulheres alocadas em casa tinham que negociar regularmente com o exterior acerca de assuntos relativos ao trabalho. Havia negociações e conflitos com os comerciantes sobre fornecimento de matéria prima e preços para as mercadorias prontas. Consideremos o caso da indústria do bidi. Aqueles que produziam bidis normalmente iam em grupos coletar e entregar estoques. Na produção de bidi, os abatimentos feitos pelos comerciantes tinham um caráter institucionalizado. Mas havia uma discussão regular sobre o quanto era retirado. Os cálculos a respeito das taxas da remuneração feitos pelas mulheres produtoras de bidi e suas noções de remuneração justa e injusta foram produzidas através de comparações entre os ganhos com a produção de bidi em Kanpur e em regiões vizinhas. Escutemos Bishnu Devi, uma trabalhadora do bidi de meiaidade, residente em Kanpur: “Nós deveríamos ganhar 22 rúpias (por 1000 bidis). Em

31 Entrevista: Sukhrani.

32 As estatísticas baseadas nos números de cada uma dessas unidades são problemáticas. Muitas delas não estão registradas como indústrias. Além disso, os cálculos tendem a atenuar o número de trabalhadores empregados e não fornecem detalhes sobre o número de mulheres empregadas. Veja, por exemplo, Statistics on Registered Units for 1999-2000, District Industries Centre, Kanpur City.

33 Ao contrário de suas vizinhas Kori, Jay Devi, de berço Kachi (uma casta de mercadores de verduras), não podia sair para conseguir matéria prima. Os homens da família faziam objeções ao seu deslocamento para fora de casa. Ela ganhava somente Rs.1 por 12 tiras, em contraste com os Rs. 1,30 e Rs. 1,40 ganhos pelos que conseguiam o material por si próprios. Entrevista, Jay Devi. 
Saharanpur eles pagam 27 rúpias, em Jhansi 35 rúpias, em Urai 22, enquanto nós ganhamos 15 rúpias.". ${ }^{34}$

A maioria dos comerciantes retirava uma parcela de cerca de $15 \%$ além do número firmado em contrato. Assim, as produtoras de bidi tinham que lutar continuamente contra extorsões e trabalho mal pago, isso somado à baixa qualidade da matéria prima fornecida a elas. A perspectiva afiada das mulheres neste tipo de assunto e as estimativas detalhadas de lucro e perda que elas apresentavam se contrapõem às imagens padrão das mulheres como dóceis e sem sabedoria mundana. ${ }^{35}$

Havia também conflitos maiores sobre preços quando as mulheres negociavam coletivamente as taxas com os comerciantes. As mulheres mais velhas que produziam bidis desde sua infância tinham memória de tempos em que seus ganhos eram mais baixos. ${ }^{36}$ Seus relatos do passado, no entanto, tendem a apagar as memórias de protesto: elas negam qualquer agência das mulheres. Greves e protestos são recordados em momentos de desespero, para apontar a ineficácia de sua voz coletiva. Ainda assim, suas memórias de greves fracassadas em tempos recentes nos proporcionam elementos para pensar as maneiras como as mulheres se faziam visíveis na esfera pública. Uma produtora de bidi lembrou:

\footnotetext{
"Recentemente as produtoras de bidi lançaram uma grande greve pedindo preços maiores. Mas não há unidade. Mulheres de duas localidades se juntaram. Mas a manufatura de bidis é feita em outras dez áreas. Se todas tivessem parado de trabalhar... Nós entramos e as mulheres de Darshanpurwa entraram. Nós fizemos uma procissão até a corte do distrito".
}

Ela continua contando como havia 150 mulheres marchando em procissão para a fábrica de bidi em Nayaganj. A importância de sua coletividade é ao mesmo tempo reconhecida e negada. É um grande momento, ainda que sua grandeza seja encoberta por uma sensação de desânimo. Em sua narrativa o evento dá corpo a uma unidade ausente.

\footnotetext{
34 Entrevista, Bishnu Devi.

35 Maya, uma produtora de bidi, faz a pergunta: "Se o comerciante de bidi ganha tanto de cada produtor de, a quanto isso chega? Alguns fornecem 4000, outros 5000 bidis e se eles tem que dar 150 a mais para cada mil, a quanto isso chega?". Ela continua para fazer um cálculo elaborado do lucro dos comerciantes: "Cada pacote vale Rs.2 e ele fica com 90 pacotes de cada 1000, então quanto ele leva? E tudo que ele dá é Rs. 23 por 1000 bidis". Entrevista, Maya, 13.4.2001.

${ }^{36}$ A taxa por 1000 bidis nas Províncias centrais, na década de 1940, era de 11-13 annas e na década de 1980, Rs. 4-7. Labour Investigation Committee: Report on an Enquiry into the Conditions of Labour in the Bidi, Cigar and Cigarette Industry, 1946. New Delhi, 1946,p.11, National Commisssion on Self-Employed Women in the Informal Sector 1987, p.13.
} 
Narrativas como esta questionam as separações rígidas entre público e privado. Marcos explicativos que assumem que uma marginalização das mulheres das formas visíveis de trabalho levaram à reclusão e domesticidade tendem a fechar as fronteiras entre os espaços - entre o mundo de dentro e o de fora. As histórias das mulheres, ao contrário, trazem os processos através dos quais essas fronteiras foram negociadas e as linhas entre dentro e fora foram embaralhadas e redesenhadas. Não é como se a esfera pública se tornasse menos masculina, mas para as mulheres, sua presença fora é importante para reconstituir suas vidas individuais. No atual cenário, em que o trabalho fabril encolheu e os trabalhadores homens estão desempregados, os espaços através dos quais os homens da classe trabalhadora de cidades como Kanpur extraíam suas identidades estão sob ameaça.

Enfatizo neste artigo a necessidade de repensar as noções de trabalho e domesticidade. Embora as idéias de reclusão e domesticidade sejam importantes, a noção de uma mudança unilinear é problemática. As experiências foram múltiplas: as famílias da classe trabalhadora implementaram diversas estratégias para enfrentar as questões de trabalho e de falta dele. Este ensaio sugere que as mulheres empurraram as fronteiras do patriarcado, criando espaços dentro dele. Ainda assim, não é que elas estivessem continuamente resistindo às estruturas de controle. A transgressão de fronteiras pode conviver com conformidade, renegociações e modificação. Textos críticos sobre a família e o trabalho das mulheres na América Latina, feitos desde a década de 1990 por Tinsman, Klubock, Nunez, entre outros, questionam idéias canônicas sobre a família e a autoridade patriarcal e examinam as formas em que as relações de poder foram reconfiguradas e em que os conceitos binários de público e privado que relegavam as mulheres a um domínio interior de conformidade foram desafiados. ${ }^{37}$

O trabalho remunerado num contexto em que os homens estão cada vez mais desempregados é importante para dar às mulheres a sensação de poder para definir estratégias familiares. Mesmo para aquelas envolvidas nos trabalhos feitos em casa, a domesticidade não significou a ausência da esfera pública. Mulheres envolvidas em trabalhos feitos em casa tinham que interagir regularmente com clientes, comprando

\footnotetext{
37 Ver, por exemplo, KLUBOCK, Thomas "Writing the History of Women and Gender", NUNEZ, Lorena, "Women on the Streets: Vending and Public Space in Chile", Economic and Political Weekly, 28:44, October 1993, pp. WS 61-71, WS 74-82, SAFA, Helen, The Myth of the Male Breadwinner: Women and Industrialization in the Caribbean Oxford: Westview Press, 1995 e TINSMAN, Heidi, "Politics of Gender and Consumption".
} 
material e vendendo mercadorias. Interações como estas, ainda que limitadas, foram importantes para dar às mulheres maior controle sobre suas vidas e poder de barganha em relação aos seus compatriotas homens.

\section{REDEFININDO OS ESPAÇOS DE GÊNERO}

Num cenário em que as indústrias tradicionais de larga escala estão em recuo e crise, a natureza da força de trabalho está sendo rapidamente transformada. Se a fase de expansão industrial foi acompanhada de uma masculinização da força de trabalho, é provável que hoje uma feminização da força de trabalho esteja ganhando espaço. 0 processo de feminização da força de trabalho está acontecendo em dois níveis. Primeiro, há troca de homens por mulheres com o afastamento dos homens do trabalho fabril e o emprego das mulheres nas indústrias domésticas. Este trabalho feminizado, porém, permanece invisível aos olhos do público. Ele não apenas está atrelado a formas invisíveis em indústrias domésticas como não é registrado nas estatísticas oficiais. Em segundo lugar, há uma mudança na psicologia social dos trabalhadores - um sentimento de perda de masculinidade. Para os homens empregados em indústrias, o trabalho fabril ordenava um status social que definia sua masculinidade e identidade. O trabalho dava a eles um sentimento de poder, um status dentro do mundo masculino urbano. Hoje, as narrativas dos homens trabalhadores exibem imagens de decadência e envelhecimento, fazendo comparações entre seus corpos e as máquinas surradas da fábrica. ${ }^{38} \mathrm{~A}$ perda de trabalho atualmente implica mais que uma perda econômica, significa também uma perda de masculinidade, uma emasculação, uma desestabilização da autoridade masculina dentro da família.

As experiências dos trabalhadores na atual fase da industrialização são também mediadas pelas equações de gênero dentro da família e da casta de origem. Em um mercado de trabalho em que os trabalhos para homens estão diminuindo, os ganhos das mulheres estão se tornando crescentemente importantes como estratégia de sobrevivência. Ainda

\footnotetext{
38 Para uma elaboração deste argumento veja JOSHI, Chitra, "Lost Worlds: Indian Labour and its Forgotten
} Histories", Permanent Black, 2003, pp. 313-29. 
assim, o trabalho das mulheres é uma ameaça para as estruturas patriarcais consolidadas, e há uma resistência contínua a ele. Mas as estratégias de negociação variam em diferentes tipos de famílias trabalhadoras.

Famílias trabalhadoras de castas mais altas, como argumentei, continuam a manter as mulheres reclusas e resistir à sua entrada nos espaços públicos, a despeito do rápido declínio da renda familiar. Mas o homem provedor empregado ou parcialmente empregado tem uma presença patriarcal na família que vem diminuindo. ${ }^{39}$ Nas famílias em que as mulheres são agora membros remunerados regulares e os homens estão intermitentemente empregados, as relações de poder em casa são freqüentemente perturbadas. Os homens em tais famílias sentem uma dupla perda: a dos seus empregos e a da autoridade masculina em casa. Ainda assim, os homens lutam para manter sua noção de individualidade. Um grande número de trabalhadores continua a definir sua masculinidade através da bebida e de sua associação a addas masculinas ${ }^{40}$. As pesquisas sobre orçamentos familiares sugerem que o gasto em bebidas alcoólicas nas famílias das castas mais baixas era mais alto que nas outras castas. $^{41}$ Os funcionários que realizam estas pesquisas duvidam da confiabilidade destas estimativas, porque as castas mais baixas tendem a exagerar suas despesas com bebida. Aqueles que trabalham como catadores de lixo e outros dejetos nas cidades, por exemplo, vêem um gasto mais alto com bebidas alcoólicas como sinal de status. O consumo de álcool num contexto de ganhos masculinos em queda envolve brigas pelos recursos domésticos e conflitos entre as noções femininas de parcimônia e a extravagância masculina. Muitas mulheres entrevistadas insistiram em afirmar que os homens tinham que conseguir sustentar suas próprias despesas com bebida. Era comum em muitas famílias que o homem gastasse o ganho do dia em bebida, enquanto as mulheres sustentavam as crianças. A

39 Veja JOSHI, Chitra, "Deindustrialization and the Crisis of Male Identities", International Review of Social History, n.47, 2002, pp.159-75.

40 Addas = encontros em que os homens conversavam, trocavam notícias e estabeleciam laços de amizade. Um estudo da década de 1960 mostra que o consumo de bebidas alcoólicas era mais comum em distritos industriais como Kanpur. Por volta de 70\% dos trabalhadores em Kanpur eram consumidores ocasionais e 30$50 \%$ consumidores regulares, que gastavam uma média de $20-25 \%$ dos seus salários em bebida alcoólica, a quantia subindo para 50\% no caso dos homens solteiros. Report of the Study Team on Prohibition. Vol II, 1964. p.227.

41 De acordo com uma pesquisa da década de 1930, os gastos com bebida entre os varredores 'intocáveis' era mais alto que nas outras castas. Os pesquisadores notaram: "Quando começamos nossa pesquisa descobrimos que a maior parte dos varredores orgulhava-se da quantia que gastavam em tóxicos, essa quantia sendo vista como uma espécie de índice de status social.'. Report of the Harijan Survey Committee 1933-34 (Kanpur 1934), p.30. 
imprudência diante da adversidade era para eles uma afirmação do orgulho masculino. A auto-afirmação masculina também tomava a forma de crescentes agressões em casa. Os sentimentos de emasculação e perda do orgulho eram temporariamente esquecidos através de demonstração de poder físico perante as mulheres. Mulheres em muitas famílias das castas mais baixas eram quase resignadas à idéia de homens bêbados batendo nelas durante a noite. A realidade brutal da vida cotidiana, em última instância, estruturava as relações de poder na família. Isto não significa traçar uma ligação necessária entre o sentimento de emasculação e a violência contra a mulher. Mas, de qualquer forma, sugiro que o doméstico se torna um domínio mais disputado quando os espaços de afirmação da masculinidade que existiam antes se deslocam. Os padrões estabelecidos de agressão masculina são intensificados numa situação em que a própria identidade dos homens está em questão.

O declínio das indústrias tradicionais e a expansão do setor informal no presente contexto, assim, têm implicações culturais profundas. A erosão de espaços em torno dos quais a cultura do trabalho e do lazer foram construídas criou uma crise de identidades masculinas. Para os homens, ser um berozgar (desempregado) significava uma perda dupla - um colapso dos seus mundos exteriores e uma presença patriarcal diminuída na família. A invisibilização dos homens na força de trabalho toca até o espaço interior do doméstico ameaçando a autoridade masculina na família, desequilibrando equações de gênero. Dentro deste cenário, movimentos que se mobilizam em torno de políticas de ódio e violência comunal ganham espaço, acabando com tradições de solidariedade e coletividade da classe trabalhadora construídas no passado.

\section{CONCLUSÃO}

As mulheres nunca foram a maior porção da força de trabalho na indústria organizada na Índia e a porcentagem que ocupam na força de trabalho total caiu na maior parte dos centros industriais desde o início do século XX. Para onde recuaram as mulheres? O que há por trás de sua invisibilidade? O que ocorreu foi uma simples mudança do trabalho para a domesticidade, da esfera pública para as reentrâncias do interior da família? Sustentei aqui que precisamos nos mover para além dos termos da polêmica do provedor e olhar para como as mulheres redefiniram as noções de domesticidade nas práticas cotidianas. 
A necessidade de repensar é particularmente importante no contexto em que as indústrias fabris estão em declínio, o fechamento de fábricas está dizimando a classe trabalhadora fabril e o trabalho visível e invisível das mulheres tem se tornado cada vez mais importante. ${ }^{42} \mathrm{Na}$ verdade, a relação permanente delas com o trabalho tornou-se a base para a emergência da "mulher provedora" no presente. Para muitas famílias, a subsistência regular vem do trabalho remunerado feito em casa pelas mulheres. Tentei explorar o que isso significou para o âmbito doméstico, como reconfigurou estruturas de poder dentro dele e como redefiniu estratégias de sobrevivência.

42 É praticamente impossível fornecer estimativas sobre os números de mulheres empregadas nas diferentes indústrias domésticas. A maior parte delas é empregada de miríades de pequenos contratantes. Trabalhadoras do bidi, por exemplo, são protegidas por uma regulamentação de salário mínimo, que ainda continua amplamente não implementada. Os empregadores são relutantes em registrar as mulheres ou em fornecer a elas qualquer forma de identificação como empregadas. Quando os nomes são inseridos, normalmente são os dos homens chefes de família e não os das funcionárias mulheres. Report of the National Commission on SelfEmployed Women and Women in the Informal Sector (1987). 